\title{
7th International Conference on Semiconductor Photochemistry (SP7)
}

\author{
Elena Selli ${ }^{1}$. Detlef Bahnemann ${ }^{2}$
}

Accepted: 23 October 2021 / Published online: 6 November 2021

(C) The Author(s), under exclusive licence to Springer Science+Business Media, LLC, part of Springer Nature 2021

This special issue of Topics in Catalysis (Semiconductor Photocatalysis: Future Perspectives) collects contributions presented at the 7th International Conference on Semiconductor Photochemistry (SP7), which was held on September 11-14, 2019 in Milano, Italy, in the beautiful Renaissance $\mathrm{Ca}$ ' Granda central building of the University of Milan. The conference saw the active participation of more than 160 attendants in an intense program, including 12 plenary and keynote lectures, 60 oral presentations, 20 flash presentations by young scientists and 2 poster sessions.
This Special Issue collects a series of original contributions presented within the SP7 conference and a review paper, which well highlight the main aim of the conference to cover the current developments in the area of semiconductor photochemistry and photo(electro)catalysis, specifically focusing on either new findings related to "historical" $\mathrm{TiO}_{2}$-based materials or to up-to-date results obtained with emerging novel semiconductor photo(electro)catalytic materials.

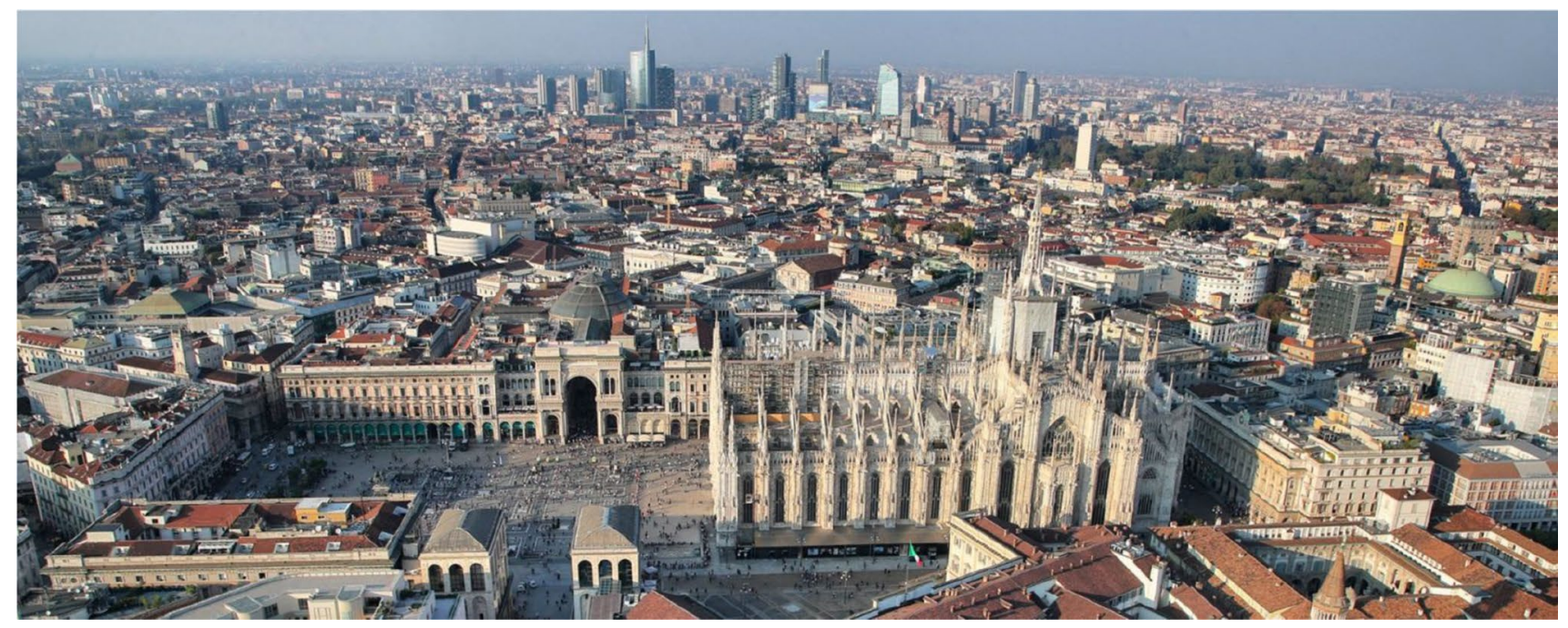

Elena Selli

elena.selli@unimi.it

1 Department of Chemistry, University of Milan, Milan, Italy

2 Institute of Technical Chemistry, Leibniz Universität

Hannover, Hannover, Germany 
One approach to decrease the cost of photoactive materials, while maintaining a high photon conversion efficiency consists in mixing the photocatalyst with cheaper additives while avoiding significant activity losses. A new model, based on fractal kinetics, is presented by Bahnemann's group and employed to fit transient absorption decays in $\mathrm{TiO}_{2}$ mixtures with binary particle size distributions and in $\mathrm{TiO}_{2}$ mixtures with a priori inert additives. In both cases, the insights obtained from the model were crucial to explain the photocatalytic activities of the mixtures.

In their work on the microwave-assisted synthesis of heterojunctions based on bismuth niobate $\left(\mathrm{BiNbO}_{4}\right)$ and tungsten oxide $\left(\mathrm{WO}_{3}\right)$, to be used as photoanodes for water splitting under simulated solar light, J.S. Souza and coworkers show that a control of the temperature and irradiation power allows tuning the fraction of orthorhombic and triclinic phases in $\mathrm{BiNbO}_{4}$ nanoparticles, which are able to generate photocurrent densities more than one order of magnitude higher than bare $\mathrm{WO}_{3}$.

The paper by Marcì et al. reports on the selective photocatalytic oxidation of 5-hydroxymethyl-2-furfural 2,5-furandicarboxyaldehyde under natural solar irradiation in a batch reactor, employing meso-tetra aryl substituted porphyrins either metal-free or containing $\mathrm{Cu}$ (II) or $\mathrm{Zn}(\mathrm{II})$ complexes, supported on graphitic or thermo-exfoliated carbon nitride $\left(\mathrm{C}_{3} \mathrm{~N}_{4}\right)$.

A new composite material with an enhanced bactericidal action was proposed by Danilenko et al., exploiting the mechanical interactions of the bacteria with $\mathrm{ZnO}$ tetrapod spikes, a photocatalytic process on $\mathrm{ZnO}$ nanoparticles, and disinfection by Ag nanoparticles, which allowed a significant decrease in the concentration of bacteria in indoor air.

The review paper written by Liu et al. highlights the recent experimental and bandgap computational breakthroughs in the photocatalytic properties of bismuth oxides and halides, and also provides guidelines for the rational design and fabrication of highly efficient bismuth-based materials for future research directions, water treatment in particular.

In their paper titled "Photoactive widegap oxide doped $\mathrm{ZnO}$ with non-stoichiometric matrix: aspects of formation" O. Gorban and co-workers used various spectroscopic techniques for the description of the characteristics of investigated systems and for the determination of structure forming mechanisms in $\mathrm{Al}, \mathrm{Zr}$ or $\mathrm{Ce}$ doped non-stoichiometric $\mathrm{ZnO}_{1-\mathrm{x}}$. Thereby, they were able to show that additional reactive oxygen species, in particular, super-anion radicals $\left(\mathrm{O}_{2}{ }^{--}\right.$, ROS $)$are formed in Ce-doped $\mathrm{ZnO}$ thereby improving the activity of the material. As a result, an increase of the photocatalytic phenol degradation by $30 \%$ compared to pure $\mathrm{ZnO}$ may be achieved by the choice of Ce-doped $\mathrm{ZnO}$ catalysts.

M. E. Simonsen et al. used principal component analysis (PCA) to study the effect of batch, reduction temperature, $\mathrm{TiO}_{2}$ content and UV-C irradiation on surface energy, polarity and interlayer spacing of photoactive $\mathrm{TiO}_{2} / \mathrm{GO}$ (graphene oxide) composite membranes. Two PCA models were successfully developed. While the first model shows a negative correlation between reduction temperature and d-spacing, the second model nicely explains the effect of UV-C activation on the surface energy of the $\mathrm{TiO}_{2} / \mathrm{GO}$ composite membranes.

A series of $\mathrm{Sc} / \mathrm{V}$ co-doped rutile $\mathrm{TiO}_{2}$ with different $\mathrm{Sc} / \mathrm{V}$ ratio was synthesized by P. D. Murzin and co-workers. While an increase of the vanadium concentration in co-doped samples results in stronger absorption in the visible light range, a photocatalytic activity dependence on the co-dopant ratio demonstrates "volcano" plot behavior with a maximum at $75 / 25 \mathrm{Sc} / \mathrm{V}$ ratio, while the work function dependence on $\mathrm{Sc} / \mathrm{V}$ ratio demonstrates a negative correlation with photocatalytic activity resulting in a minimal value of work function at the same optimal ratio of co-dopant content.

Publisher's Note Springer Nature remains neutral with regard to jurisdictional claims in published maps and institutional affiliations. 